\title{
The Effect of Spectral Composition of Light on Physiological and Biochemical Characteristics of Tomatoes
}

\author{
Hasanova Kenul Zaur ${ }^{1}$, Azizov Ibrahim Vahab ${ }^{2}$ \\ ${ }^{1}$ Faculty of Agronomy, Azerbaijan State Agrarian University, Ganja, Azerbaijan \\ ${ }^{2}$ Department of Photochemistry of Chloroplasts, Institute of Biology and Biotechnology, Baku, Azerbaijan
}

Email address:

konul.qasanova.86@mail.ru (H. K. Zaur), Ibrahim.azizov47@gmail.com (A. I. Vahab)

\section{To cite this article:}

Hasanova Kenul Zaur, Azizov Ibrahim Vahab. The Effect of Spectral Composition of Light on Physiological and Biochemical Characteristics of Tomatoes. Advances in Applied Physiology. Vol. 5, No. 1, 2020, pp. 9-11. doi: 10.11648/j.aap.20200501.13

Received: April 20,2020; Accepted: May 5, 2020; Published: May 19, 2020

\begin{abstract}
The effect of white, blue and red light on the relative humidity of the leaves, as well as on the content of photosynthetic pigments, the activity of photosystem-2, the content of proteins and soluble carbohydrates in the leaves of tomato varieties were studied. Photosynthetic pigments were determined by the method of leaf homogenization, in $96 \%$ ethanol, with further centrifugation at $200 \mathrm{~g}$. Measurements were conducted using a spectrophotometer at wavelengths of 665,649 and $440.5 \mathrm{~nm}$. The content of soluble sugars was determined at wavelengths of 630-570 $\mathrm{nm}$ by the accelerated bichromate method. The protein content was determined on a spectrophotometer SP 2000, at wavelengths of 230 and $260 \mathrm{~nm}$. Studies have shown that during the influence of red light, there is a slight decrease in the protein content, an increase in the content of photosynthetic pigments and soluble carbohydrates in all varieties of tomatoes grown in red light. Unlike red light, blue light stimulated the synthesis of proteins in leaves. Red light promotes the synthesis and accumulation of carbohydrates, while blue light encourages the synthesis of proteins in tomato leaves.
\end{abstract}

Keywords: Blue Light, Red Light, Pigments, Photosystem-2, Proteins, Carbohydrates

\section{Introduction}

One of the essential factors necessary for the growth, development, and productivity of plants is the intensity and spectral composition of light. Under conditions of insufficient sunlight, the process of photosynthesis is disrupted, growth, development, yield, and plant resistance reduced. The response of vegetables to a lack of the sunlight is subsequently accompanied by a decrease in productivity. Among vegetable crops, tomatoes occupy a special place in response to the spectral composition of light. Among the plant receptors that perceive external light signals, the system of phytochromes plays the most writing role $[1,2,6,8,10]$. Three classes of photoreceptors included in this system are: phytochromes, cryptochromes, and phototropins. Phytochromes perceive and transduce a light signal in the red region (660-730 nm). Plants contain at least five phytochromes - A, B, C, D, and E, which differ in the physiological role [11]. Phytochromes control the growth, development, plant morphogenesis, the activity of enzymes, synthesis of ribulose-1,5-bisphosphate of carboxylase, chlorophyll, photosynthesis intensity, accumulation, and distribution of assimilates. However, in most works, only quick response to the effect of red light studied. There is only a small number of works devoted to the study of the action of red light in field experiments. Therefore, research in this direction seems appropriate.

The aim of our research was to study the effect of white, blue and red light on some physiological and biochemical parameters of tomatoes.

\section{Materials and Methods}

Five tomato varieties (Lycopersicon esculentum Mill.) were used in the work: early ripening variety Volgograd, highly productive variety Tolstoy, mid-ripening varieties Falkon, 2224, and Rally. Plants were grown in an experimental plot on plots with an area of $1 \mathrm{~m}^{2}$. The pilot plants were coated with a transparent film transmitting light at wavelength of 420-480 $\mathrm{nm}$ and 620-680 nm during the growing season (June - July). For physiological and biochemical studies, samples of fully formed leaves were taken every week at 11 o'clock. Photosynthetic pigments were determined by homogenizing 
leaves in $96 \%$ ethanol, further centrifuging at $200 \mathrm{~g}$. The content of chlorophyll a, b and carotenoids was determined on a spectrophotometer at wavelengths of 665,649 and $440.5 \mathrm{~nm}$, using the coefficients of Wintermans, De Mots, 1965 [11]. The activity of photosystem 2 was determined using a $F_{v} / F_{m}$ coefficient, where $\mathrm{F}_{\mathrm{v}}=\mathrm{F}_{\mathrm{m}}-\mathrm{F}_{0} ; \mathrm{F}_{0}$ - fluorescence of "dark" leaves, $\mathrm{F}_{\mathrm{m}}$ - fluoressence of "light" leaves. The relative water content was determined by Tambussi [12]. The content of soluble sugars determined at a wavelength of $630-570 \mathrm{~nm}$ by the accelerated bichromate method [13]. The protein content was determined on SP 2000 spectrophotometer at a wavelength of 230 and $260 \mathrm{~nm}$, according to the method of Kalb, Bernlohr [14]. Data analysis and statistical analysis were conducted using Microsoft Excel. Statistical analysis was performed with the aid of the Stat graphics Plus 5.1 statistical package. The means of values were compared by Duncan's multiple range test $(\mathrm{p}=0.05)$.

\section{Results and Discussion}

The results of the experiments showed that in blue light, the morphometric and physiological parameters of tomato plants change in one direction (Table 1). The relative humidity of the leaf decreased in the Falcon cultivar - by $12 \%$, in $2224-7 \%$, Krasnodar - 8\%, Volgograd- 7\%, Tolstoy - 8\%, and in Rally$15 \%$. The content of chlorophylls and carotenoids increased in all varieties, with slight differences. The efficiency of photosystem 2 was at the same level in the Falcon and 22-74 varieties, slightly increased in the varieties Krasnodar,
Volgograd, Tolstoy, and Rally. Some decreases in carbohydrate content were observed in Falcon and Rally varieties, and a slight increase in sugar content noted in the leaves of Krasnodar and Tolstoy varieties. The results of our studies showed that in the leaves of all studied tomato varieties, an increase in the protein content occurred in blue light. Similar results were obtained in works by other researchers. It was shown [2] that the carbohydrate content changed during the day: low content of water-soluble carbohydrates was observed in the morning than in the evening, which, according to the authors, is due to the intensive inclusion of water-soluble carbohydrates in the metabolism, as well as with an increase in temperature. The authors believe that their results do not yet give a conclusion on the effect of activation of phytochromes in tomato seedlings on the content of carbohydrates in leaves and plants. However, according to other published data, the activation of phytochromes leads to an increase in the intensity of carbohydrate metabolism and the activity of carbohydrate metabolism its enzymes [3-7, 9]. These effects were established directly during the exposure period or within a day after exposure to red light. In our experiments, an increase in the content of chlorophylls and carotenoids, accompanied by the activation of the photosystem 2 and a slight decrease in the protein content also revealed. Apparently, under the influence of red light, phytochromes were activated, which leads to the acceleration of morphogenetic and physiological processes, and which can be also realize due to increased carbohydrate metabolism.

Table 1. The effect of white, blue and red light on the morphometric and physiological parameters of tomatoes.

\begin{tabular}{|c|c|c|c|c|c|c|}
\hline Tomato varieties & $\begin{array}{l}\text { Relative water content } \\
\text { of leaves, } \%\end{array}$ & $\begin{array}{l}\text { Content of chlorophylls } \\
(\mathrm{a}+\mathbf{b}),(\mathrm{mq} / \mathrm{l})\end{array}$ & $\begin{array}{l}\text { Content of } \\
\text { carotenoids (mq/l) }\end{array}$ & $F_{v} / m$ & $\begin{array}{l}\text { Content of } \\
\text { proteins, \% }\end{array}$ & $\begin{array}{l}\text { Content of } \\
\text { sugars, \% }\end{array}$ \\
\hline \multicolumn{7}{|l|}{ Falkon } \\
\hline White light & $60 \pm 2,3$ & $16,8 \pm 0,6$ & $5,9 \pm 0,2$ & 0,66 & 1,5 & 3,8 \\
\hline Blue light & $66 \pm 2,3$ & $15,5 \pm 0,4$ & $5,4 \pm 0,4$ & 0,65 & 1,9 & 3,6 \\
\hline Red light & $58 \pm 3,4$ & $19,8 \pm 1,2$ & $6,5 \pm 0,3$ & 0,67 & 1,6 & 4,2 \\
\hline \multicolumn{7}{|l|}{$22-74$} \\
\hline White light & $63 \pm 1,1$ & $18,2 \pm 0.5$ & $6,1 \pm 0,1$ & 0,68 & 1,8 & 4,1 \\
\hline Blue light & $69 \pm 1,2$ & $15,6 \pm 1,4$ & $5,8 \pm 0,2$ & 0,65 & 2,1 & 3,8 \\
\hline Red light & $64 \pm 0,8$ & $20,2 \pm 2,1$ & $6,9 \pm 0.1$ & 0,69 & 1,8 & 4,6 \\
\hline \multicolumn{7}{|l|}{ Krasnodar } \\
\hline White light & $75 \pm 1,3$ & $18,2 \pm 1,3$ & $6,5 \pm 0,3$ & 0,73 & 1,9 & 4,2 \\
\hline Blue light & $77 \pm 2,4$ & $16,7 \pm 1,1$ & $6,2 \pm 0,2$ & 0,72 & 2,3 & 4,1 \\
\hline Red light & $71 \pm 1,9$ & $21,2 \pm 2,5$ & $7,6 \pm 0,5$ & 0,75 & 1,8 & 4,7 \\
\hline \multicolumn{7}{|l|}{ Volgograd } \\
\hline White light & $70 \pm 0,9$ & $21,2 \pm 0,9$ & $7,8 \pm 0,2$ & 0,74 & 2,1 & 4,3 \\
\hline Blue light & $72 \pm 0,8$ & $18,6 \pm 0,6$ & $7,5 \pm 0,4$ & 0,71 & 2,5 & 4,1 \\
\hline Red light & $67 \pm 1,2$ & $23,2 \pm 1,9$ & $8,4 \pm 0,6$ & 0,76 & 1,8 & 4,8 \\
\hline \multicolumn{7}{|l|}{ Tolstoy } \\
\hline White light & $80 \pm 1,2$ & $24,2 \pm 0.5$ & $8,6 \pm 0,4$ & 0,75 & 2,1 & 4,4 \\
\hline Blue light & $82 \pm 0,7$ & $20,4 \pm 0,6$ & $8,2 \pm 0,3$ & 0,72 & 2,4 & 3,9 \\
\hline Red light & $75 \pm 1,3$ & $26,5 \pm 1,7$ & $9,5 \pm 0,6$ & 0,76 & 1,7 & 4,9 \\
\hline \multicolumn{7}{|l|}{ Ralli } \\
\hline White light & $75 \pm 1,5$ & $23,4 \pm 1,2$ & $8,4 \pm 0,2$ & 0,63 & 2,3 & 3,6 \\
\hline Blue light & $77 \pm 2,6$ & $19,6 \pm 1,8$ & $7,9 \pm 0,5$ & 0,61 & 2,6 & 3,5 \\
\hline Red light & $65 \pm 3,1$ & $25,5 \pm 2,1$ & $8,7 \pm 0,6$ & 0,69 & 1,5 & 4,2 \\
\hline
\end{tabular}




\section{Conclusion}

Under the influence of red light, the biosynthesis of carbohydrates is activated, and under the influence of blue light, the biosynthesis of proteins is enhanced in tomato leaves. It is recommended that for the production of fruits containing many sugars, red rays should prevail in the total light stream and, for the production of fruits containing proteins, blue rays.

\section{References}

[1] Shegolev A. S., Zhmurko V. V. 2006. The effect of red light on the productivity of tomatoes. News of the Kharkiv National Agricultural University. Seriya "Biology". No. 1 (8). - pp. 7781

[2] Shegolev A. S., Zhmurko V. V. 2008. The effect of red light on the carbohydrate content in tomato leaves. News of the Kharkiv National Agricultural University. Seriya "Biology". No. 814. (7). pp. 205-210.

[3] Mustilli A. C., Bowler C. 1997. Tuning in to the signals controlling photoregulated gene expression in plants. The EMBO Journal. Vol. 16, №19. pp. 5801-5806.

[4] Mustilli A. C., Fenzi F., Ciliento R. et al. 1999. Phenotype of the tomato high pigmentmutant is caused by a mutation in the tomato homolog of DEETIOLATED1. Plant Cell. Vol. 11. pp. $145-158$.

[5] Neuhaus G., Bowler C., Hiratsuka K. et al. 1997. Phytochromeregulated repression of gene expression requires calcium and cGMP. The EMBO Journal. Vol. 16, №10. pp. 2554-2564.
[6] Parks B. M. 2003. The red side of photomorphogenesis. Plant Physiology. Vol. 133. pp. 1437-1444.

[7] Peters J. L., Széll M., Kendrick R. E. 1998. The expression of light-regulated genes in the high-pigment-1 mutant of tomato. Plant Physiol. Vol. 117. pp. 797-807.

[8] Schäfer E., Bowler C. 2002. Phytochrome-mediated photoperception and signal transduction in higher plants. The EMBO Journal. Vol. 3, №11. pp. 1042-1048.

[9] Sharkey T. D., Vassey T. L., Vanderveer P. J., Vierstra R. D. 1991. Carbon metabolism and photosynthesis in transgenic tobacco (Nicotiana tabacum L.) having excess phytochrome. Plant Physiol. 185. pp. 287-296.

[10] Smith H. 1995. Physiological and ecological function within the phytochrome family. Annu. Rev. Plant Physiol. Plant Mol. Biol. Vol. 46. P. 289-315.

[11] Gavrilenko V. F., Zhigalova T. V. 2003. Great workshop on photosynthesis. "M. ACADEMIA". 254 p. (In Russian).

[12] Tambussi E. A., Noges S., Araus L. 2005. Ear of durum weaht under weather stress. Water relations and phothosyntetic metabolism. Planta. pp. 1-25.

[13] The large workshop "Biochemistry". 2012. Laboratory work: textbook. comp. M. G. Kusakin, V. I. Suvorov, L. A. Chudinova; Perm. state nat. researched un-t. - Perm, 148 p. (In Russian).

[14] Kalb, V. F. and Bernlohr, R. W., 1977. A new spectrophotometric assay for protein in cell extracts. Analyt. Biochem., 82: 362-371. 